\title{
Evaluation of Effectiveness of Anti Hangover Oral Film in the Management of Alcohol Induced Hangover Symptoms
}

\author{
J. C. Shobha* and Tabitha Ohol \\ Department of Clinical Pharmacology and Therapeutics, Hetero Healthcare Ltd., Hyderabad - 500081, \\ Telangana, India; Shobhaudutha@heterohealthcare.com
}

\begin{abstract}
Alcohol induced hangover symptoms are experienced the day after alcohol consumption. Curcumin is polyphenolic compound available in turmeric with strong antioxidant and anti-inflammatory properties. Curcumin is tested as one of the best, in alleviating the hangover symptoms. The anti-hangover properties of curcumin were evaluated in the present study. 42 subjects received the active anti-hangover oral film and 16 subjects received placebo. Subjects who received the active anti-hangover oral film showed complete absence of symptoms like dizziness, stomach ache and palpitation as compared to placebo. $2-5 \%$ of the subjects in the active group experienced headache, loss of appetite and nausea as compared to $56 \%$ to $87 \%$ in the placebo group. There was no problem with concentration at work in $71 \%$ of the subjects in the active group as compared to $38 \%$ in the placebo group. Relief from hangover symptoms was good to excellent in the active group as compared to no relief in the placebo group. The anti-hangover oral film containing curcumin was safe and effective in minimizing or completely eliminating the hangover symptoms.
\end{abstract}

Keywords: Alcohol, Curcumin, Film, Hang Over

\section{Introduction}

The commonly reported negative consequence of drinking alcohol is hangover ${ }^{1}$. Most of the heavy drinkers acknowledge that they have experienced hangover sometime in the past ${ }^{2}$. The common characteristic features of alcohol hangover are the feeling of general misery, and several symptoms such as headache, thirst, sleepiness and problems with concentration at work ${ }^{3}$. The symptoms of hangover are unpleasant, with a feeling of depression as it impairs cognition and the ability to drive leading to the risk of accidents ${ }^{3}$. There is a clear need for development of an effective treatment that prevents or reduces these hangover symptoms. There are many hangover cures available. Some are backed by scientific evidence, like functional foods. One such useful functional food in the management of hangover is turmeric and its polyphenolic component curcumin ${ }^{4}$.

Lipid peroxidation is induced by alcohol consumption and damages the liver cells. Curcumin being a potent anti-oxidant, protects the liver by rapid removal of these toxins ${ }^{5}$. The alcoholic fatty liver is the early stage of alcohol induced liver disease. Curcumin benefits by regulating the fat metabolism. Inflammation of gastric mucosa may trigger vomiting and nausea which is felt during hangover. Turmeric is gastro-protective and prevents any damage to the stomach and intestinal linings. The potential benefits of the phytonutrient curcumin, present in turmeric has been widely researched and human studies have confirmed that it would be safe to use it as an adjunct therapy for

\section{*Author for correspondence}


alcoholism as it maintains the membrane structure, integrity and functions in protecting GIT, liver, brain and kidney from alcohol intoxication through its natural antioxidant defences and aids in systemic recovery.

Alcohol hangover affects the daily activities and to prevent or reduce the hang over symptoms, Azista Industries have developed an anti-hangover oral film with curcumin as the main ingredient. Hence, the present study was undertaken to evaluate the effectiveness of anti-hangover oral film $(45 \mathrm{mg})$, in the management of alcohol induced hangover symptoms and also evaluate the consumer satisfaction to relief from hangover symptoms.

\section{Subjects and Methods}

The adults more than 18 years of age, consume alcohol and with a previous history of hangover symptoms were included into this open label, comparative, randomized, cross over prospective clinical study after taking their written informed consent. At entry, the age and gender were recorded on the CRF.

The present study is a placebo controlled, cross over study. As per the randomization either the anti-hangover oral film $45 \mathrm{mg}$ or placebo was asked to take orally once before the intake of alcohol. The clinical evaluation was performed in the following day morning of the alcohol consumption, for thirst, tiredness, headache, dizziness, loss of appetite, stomach ache, nausea, heart racing (palpitation) and problem with concentration at work ${ }^{6}$. The severity of symptoms was scored on a four-point scale as none/mild/moderate/severe. Good, very good and excellent rating for satisfactory relief from hangover symptoms was carried out by the study participants in both the groups. Approximately one third of the subjects were crossed over to the other formulation after one week

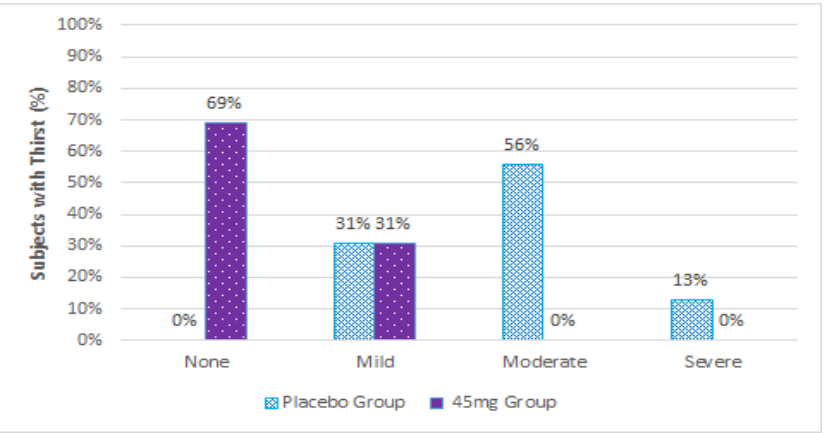

Figure 1. Percentage (\%) of subjects with thirst wash out period as per randomization. The placebo oral film contained other ingredients except curcumin, the active ingredient.

\section{Results}

Forty-two subjects received $45 \mathrm{mg}$ anti- hangover oral film containing curcumin (Active group) and 16 subjects received placebo (Placebo group). The mean age of the subjects in the active group was $33.3 \pm 7.32$ years and in the placebo group it was $37.7 \pm 5.80$ years. Severity of hangover symptoms is shown in Table 1 .

Mild to severe grade of thirst was felt by all the subjects in the placebo group as compared to $31 \%$ in the active group (Figure 1). Tiredness and headache was experienced by $87 \%$ of the subjects in the placebo group as compared to $7 \%$ and $2 \%$ in the active group respectively (Figures 2 and 3). Mild to moderate intensity of dizziness and loss of appetite was felt by $56 \%$ of subjects in the placebo group as compared to none and $2 \%$ respectively in the active group (Figures 4 and 5). 62\% of the subjects experienced nausea as compared to $5 \%$ in the active group (Figure 6). However, none of the subjects had neither stomach ache nor palpitation in the active group as compared to $38 \%$ and $31 \%$ in the placebo group respectively (Figures 7 and 8 ).

Problem with concentration at work was present in $62 \%$ of subjects in the placebo group as compared to $29 \%$ in the active group (Table 2). Good, very good and excellent relief from hangover symptoms was expressed by $10 \%, 64 \%$ and $26 \%$ of the subjects in the Active group respectively, as compared to none in the Placebo group.

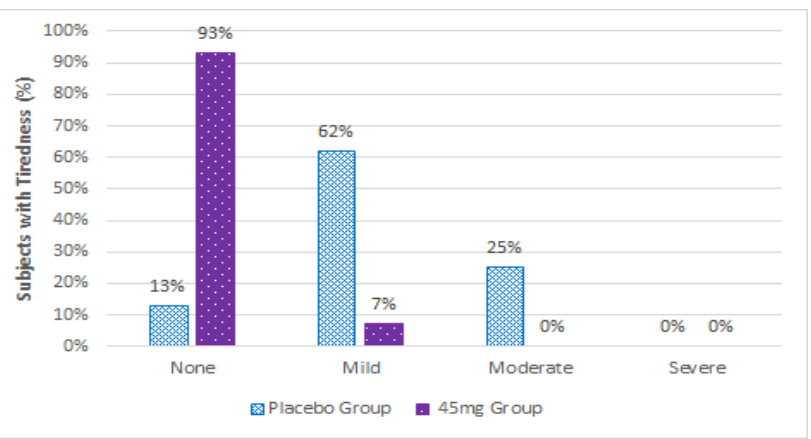

Figure 2. Percentage (\%) of subjects with tiredness 


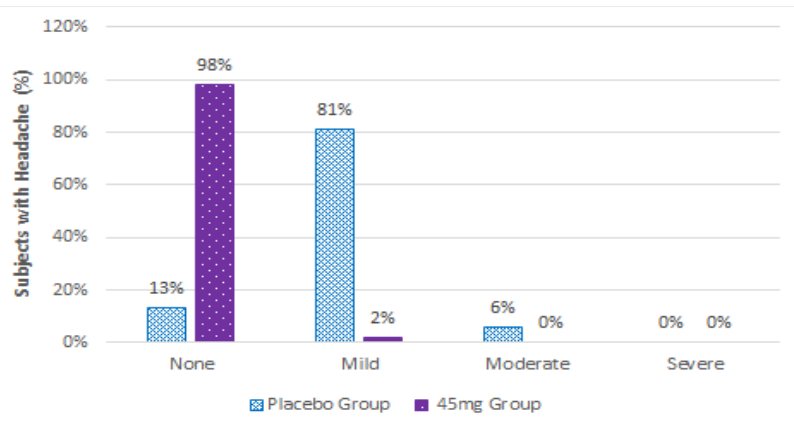

Figure 3. Percentage (\%) of subjects with headache

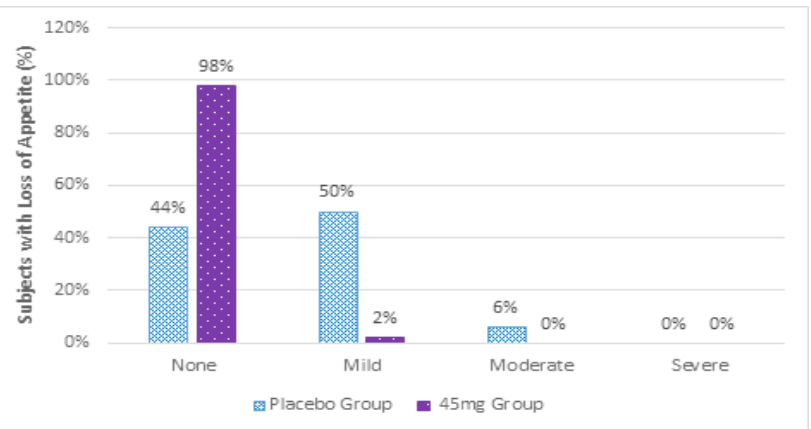

Figure 5. Percentage (\%) of subjects with loss of appetite

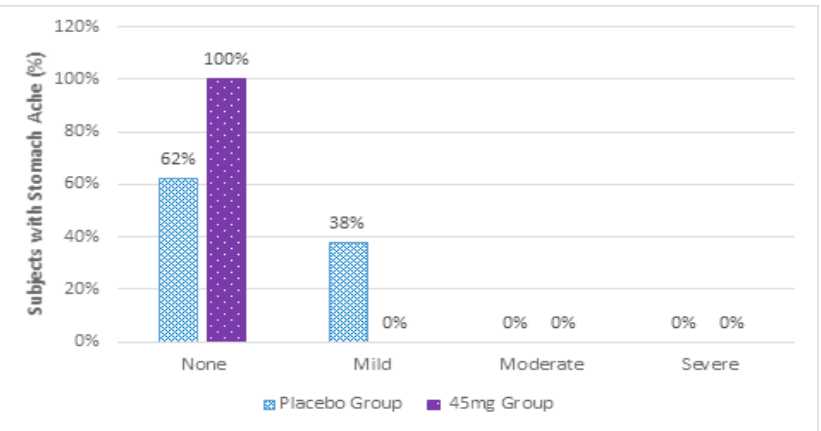

Figure 7. Percentage (\%) of subjects with stomach ache

\section{Discussion}

Alcohol induced hangover is a physiological state which includes the unpleasant effect, the following day after alcohol consumption. Hangover begins when blood alcohol concentration reduces and the acetaldehyde level

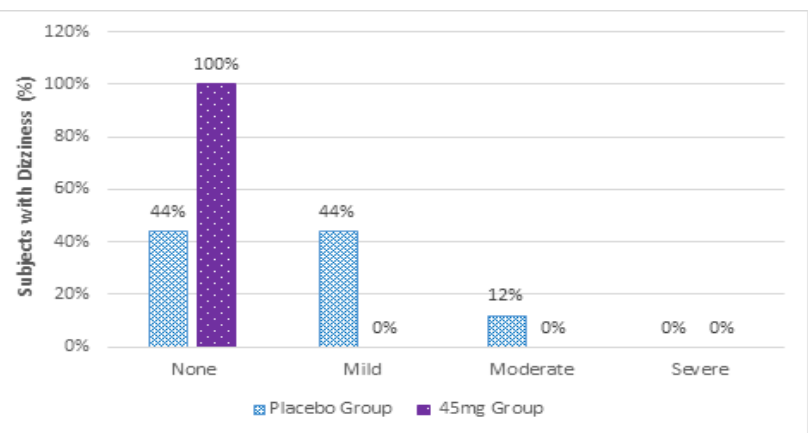

Figure 4. Percentage (\%) of subjects with dizziness

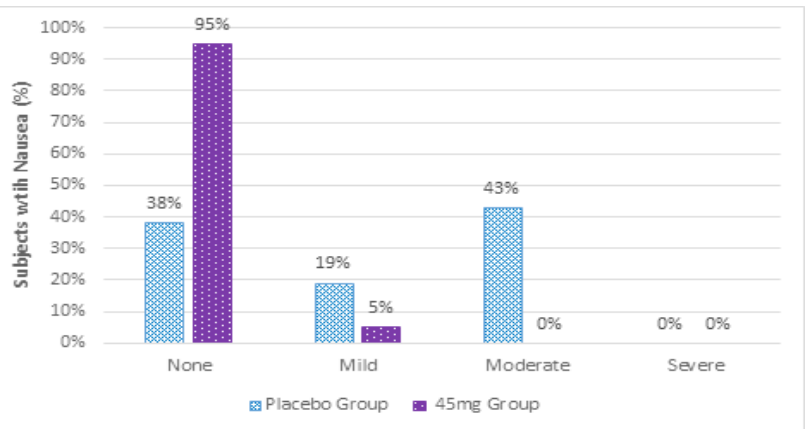

Figure 6. Percentage (\%) of subjects with nausea

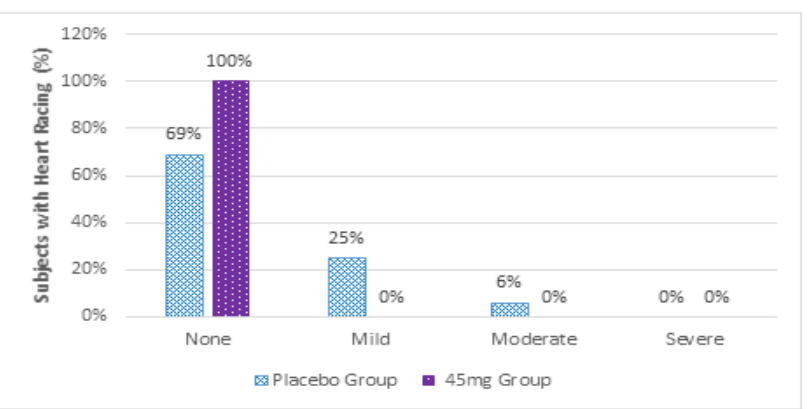

Figure 8. Percentage (\%) of subjects with Heart racing (Palpitation)

increases. This is characterized by a cluster of physical, metabolic and psychological symptoms which include fatigue, headache, thirst, dizziness, stomach ache, problems with concentration at work. The hangover symptoms experienced in our study were consistent with those mentioned in the previous studies ${ }^{7,8}$. 
Table 1. Severity of Hangover symptoms.

\begin{tabular}{|c|c|c|c|}
\hline Symptom & Severity & $\begin{array}{c}\text { Placebo Group }(n=16) \\
n(\%)\end{array}$ & $\begin{array}{c}\text { Active Group ( } n=42) \\
n(\%)\end{array}$ \\
\hline \multirow{4}{*}{ Thirst } & None & $0(0)$ & $29(69)$ \\
\hline & Mild & $5(31)$ & $13(31)$ \\
\hline & Moderate & $9(56)$ & $0(0)$ \\
\hline & Severe & $2(13)$ & $0(0)$ \\
\hline \multirow{4}{*}{ Tiredness } & None & $2(13)$ & $39(93)$ \\
\hline & Mild & $10(62)$ & $3(7)$ \\
\hline & Moderate & $4(25)$ & $0(0)$ \\
\hline & Severe & $0(0)$ & $0(0)$ \\
\hline \multirow{4}{*}{ Headache } & None & $2(13)$ & $41(98)$ \\
\hline & Mild & $13(81)$ & $1(2)$ \\
\hline & Moderate & $1(6)$ & $0(0)$ \\
\hline & Severe & $0(0)$ & $0(0)$ \\
\hline \multirow{4}{*}{ Dizziness } & None & $7(44)$ & $42(100)$ \\
\hline & Mild & $7(44)$ & $0(0)$ \\
\hline & Moderate & $2(12)$ & $0(0)$ \\
\hline & Severe & $0(0)$ & $0(0)$ \\
\hline \multirow{4}{*}{ Loss of Appetite } & None & $7(44)$ & $41(98)$ \\
\hline & Mild & $8(50)$ & $1(2)$ \\
\hline & Moderate & $1(6)$ & $0(0)$ \\
\hline & Severe & $0(0)$ & $0(0)$ \\
\hline \multirow{4}{*}{ Nausea } & None & $6(38)$ & $40(95)$ \\
\hline & Mild & $3(19)$ & $2(5)$ \\
\hline & Moderate & $7(43)$ & $0(0)$ \\
\hline & Severe & $0(0)$ & $0(0)$ \\
\hline \multirow{4}{*}{ Stomach Ache } & None & $10(62)$ & $42(100)$ \\
\hline & Mild & $6(38)$ & $0(0)$ \\
\hline & Moderate & $0(0)$ & $0(0)$ \\
\hline & Severe & $0(0)$ & $0(0)$ \\
\hline \multirow{4}{*}{$\begin{array}{l}\text { Heart Racing } \\
\text { (palpitation) }\end{array}$} & None & $11(69)$ & $42(100)$ \\
\hline & Mild & $4(25)$ & $0(0)$ \\
\hline & Moderate & $1(6)$ & $0(0)$ \\
\hline & Severe & $0(0)$ & $0(0)$ \\
\hline
\end{tabular}

Table 2. Problem with concentration at work

\begin{tabular}{|c|c|c|c|}
\hline & & $\begin{array}{c}\text { Placebo Group (n=16) } \\
\mathbf{n}(\%)\end{array}$ & $\begin{array}{c}\text { Active Group (n=42) } \\
\mathbf{n}(\%)\end{array}$ \\
\hline \multirow{2}{*}{$\begin{array}{c}\text { Problem with } \\
\text { concentration at work }\end{array}$} & Present & $10(62)$ & $12(29)$ \\
\cline { 2 - 4 } & Absent & $6(38)$ & $30(71)$ \\
\hline
\end{tabular}


Toxicity and oxidative stress caused by alcohol are the reasons behind the psychological effects of hangover ${ }^{9}$. Curcumin is tested, as one of the best for its anti-hangover properties, as it helps in detoxifying the body and protecting the liver from all ill effects of the alcohol.

Curcumin lowers acetaldehyde levels after alcohol intoxication and helps in reducing the hangover symptoms. Curcumin significantly reverses the alcohol induced inhibition of alcohol dehydrogenase ${ }^{10}$. Studies have shown, beverages containing $30 \mathrm{mg}$ of curcumin lower the blood acetaldehyde concentration significantly (25\%) compared to those who drank water alone (control) $)^{10}$.

The findings of our study are consistent with earlier studies using curcumin in reducing the hangover symptoms ${ }^{11,12}$. Symptoms like dizziness, stomach ache and palpitation were completely absent and symptoms like headache, loss of appetite and nausea were noted only in $2-5 \%$ of the subjects in the active group as compare to the placebo group indicating that curcumin oral film was highly effective in eliminating or controlling these symptoms.

Present study findings indicate that curcumin consumption reduces the severity of symptoms of alcohol induced hangover, as curcumin inhibits the effect of alcohol intoxication by reducing the acetaldehyde accumulation $^{10-12}$.

\section{Conclusion}

In the present open label, comparative, randomized, cross over, prospective clinical study with anti-hangover oral film $45 \mathrm{mg}$ containing curcumin as the main ingredient once before consumption of alcohol was effective in controlling and minimizing the hangover symptoms. The problem with concentration at work was much less in the $45 \mathrm{mg}$ group. The study medication was well tolerated without any serious adverse events. Thus, it can be concluded that $45 \mathrm{mg}$ anti-hangover oral film containing curcumin as the main ingredient can be safely and effectively used in the management of alcohol induced hangover symptoms without much problems on concentration of work, when taken before the consumption of alcohol.

\section{Acknowledgements}

Authors would like to thank Ms. S. Chan Mubeena (Research Coordinator) for helping in preparation of the manuscript. Our thanks and an appreciation goes to Mr. P. Narender Reddy (Clinical Research Associate II), in analyzing the data by providing technical support in preparation of the manuscript. Our thanks also go to Mr. Pranav Kumar Shinde for his help in statistical analysis.

\section{References}

1. Lantman MS, Mackus M, Loo AJ, Verster JC. The impact of alcohol hangover symptoms on cognitive and physical functioning, and mood. Hum Psycho pharmacol Clin Exp. 2017; 32(5). https://doi.org/10 .1002/hup.2623.PMid:28750479PMCid:PMC5638093

2. Verster JC, Herwijnen JV, Olivier B, Kahler CW. Validation of the Dutch version of the brief young adultalcoholconsequencesquestionnaire(B-YAACQ). Addict Behav. 2009;34(5):411-414. https://doi.org/10. 1016/j.addbeh.2007.09.013. PMid:17942242

3. Howland J, Rohsenow DJ, Edwards EM. Are some drinkers resistant to hangover? A literature review. Curr Drug Abuse Rev. 2008; 1(1):42-6. https://doi.org /10.2174/1874473710801010042. PMid:19630704

4. Srinivasan S, Dubey KK, Singhal RS. Influence of food commodities on hangover based on alcohol dehy drogenase and aldehydedehydrogenase activities. Curr Res Nutr Food Sci. 2019; 1:8-16. https://doi.org/10 .1016/j.crfs.2019.09.001. PMid:32914100 PMCid:PM C7473379

5. Ambade A, Mandrekar P. Oxidative stress and inflammation: Essential partners in alcoholic liver disease. Int J Hepatol. 2012. https://doi.org/10.1155/ 2012/853175. PMid:22500241 PMCid:PMC3303590

6. Prat G, Adan A, Turet MS. Alcohol hangover: A critical review of explanatory factors. Hum Psychopharmacol Clin Exp. 2009; 24:259-67. https://doi.org/10.1002/ hup.1023. PMid:19347842

7. Lantman MS, Loo AJ, Mackus M, Verster JC. Development of a definition for the alcohol hangover: Consumer descriptions and expert consensus. Curr Drug Abuse Rev. 2016; 9:148-54. https://doi.org/10.2 174/1874473710666170216125822. PMid:28215179

8. Pabst AE, Devenney LE, Verster JC. Sex differences in the presence and severity of alcohol hangover symp toms. J Clin Med. 2019; 8:867. https://doi.org/10.3390/ jcm8060867. PMid:31213020 PMCid:PMC6617014

9. Swift R, Davidson D. Alcohol hangover: Mechanisms and mediators. Alcohol Health Res World. 1998; 22(1):54-60.

10. Sasaki H, Sunagawa Y, Takahashi K, Imaizumi A, Fukuda H, Hshimoto T, et al. Innovative preparation of curcumin for improved oral bioavailability. Biol 
Pharm Bull. 2011; 34(5):660-5. https://doi. org/10.1248/bpb.34.660. PMid:21532153

11. Gopi S, Georgea R, Thankachen RU, Sriraam VT, Abirami S. Studies on the effectiveness, safety and tolerability of two doses of anti hangover drink in reducing alcohol induced hangover symptoms in adult male social drinkers. Int J Curr Res Aca. Rev. $2014 ; 2(8): 125-31$.
12. Morimoto T, Sunagawa Y, Katanasaka Y, Hirano S, Namiki M, Watanabe Y, et al. Drinkable preparation of theracurmin exhibits high absorption efficiency-a single-dose, double-blind, 4-way crossover study. Biol Pharm Bull. 2013; 36(11):1708-14. https://doi.org/ 10.1248/bpb.b13-00150. PMid:24189415 